\title{
Awareness, Attitude and Performance of Men Regarding Premenstrual Syndrome
}

\author{
Soheila Rabiepoor ${ }^{1(D)}$, Atefeh Yas $^{2^{*}(\mathbb{D}}$
}

\begin{abstract}
Objectives: Premenstrual syndrome (PMS) is among the most widely recognized conditions affecting the women of childbearing age and includes a set of physical and mental symptoms. It can also affect the relationship between couples. The purpose of this study was to determine awareness, attitude, and performance of men regarding PMS.

Materials and Methods: As a cross-sectional study, it targeted a sample of 150 men from Urmia. To gather data, awareness and performance questionnaire (Morowati Sharifabad, 2013) and a researcher-made attitude questionnaire were employed. The collected data were analyzed using SPSS version 19.0. Descriptive statistics, t-test, and Pearson correlation coefficient were used to analyze the data.

Results: Twenty-two percent of the wives of the surveyed men had PMS and during the premenstrual stage, they had experienced most of the emotional symptoms (84\%) and fluid retention (60.7\%). The mean scores of awareness, attitude, and performance of men regarding PMS were $24.2 \pm 4.45,23.93 \pm 5.35$, and $43.10 \pm 5.23$, respectively. Men whose partners had PMS recorded a higher awareness and performance scores while getting lower than average scores regarding attitude. Thus, the difference in attitude between the 2 groups was statistically significant $(P=0.04)$. Besides, there was a significant relationship among awareness, attitude and the performance of men compared to each other $(P<0.001)$.

Conclusions: Men with wives who had PMS recorded a higher awareness and performance scores while they got lower than average scores regarding attitude in comparison with the ones whose wives did not suffer from PMS. In addition, there was a significant relationship between and among awareness, attitude, and performance of men concerning PMS of their wives.

Keywords: Awareness, Attitude, Performance, Premenstrual syndrome, Men
\end{abstract}

\section{Introduction}

Premenstrual syndrome (PMS) is thought to be a standout amongst the most widely recognized disorder among the women of reproductive age (1). It consists of a series of physical and psychological symptoms that start at the end of the premenstrual period and disappears with the onset of menstrual bleeding or the first few days after menstruation. The prevalence of PMS was estimated to be close to $80 \%$ in women of reproductive age (2). Symptoms of PMS include depression, hopelessness, emotional instability, irritability, loss of interest in usual activities, difficulty concentrating, loss of energy, changes in appetite or excessive desire for food, changes in sleep habits along with physical symptoms such as breast tenderness, headache, feeling bloated and edema (3). The cause of PMS remains unknown and research findings suggest that it is multi-factorial (3). Several factors such as fluctuations in estrogen and progesterone hormones, endocrine disorders and a variety of estrogen receptors, prostaglandin synthesis and environmental factors such as alcohol consumption and stress are involved in its etiology (4). Typically, PMS is a disruptive and often a debilitating factor in the lives of many women (5) in a way that it might disrupt interpersonal relations and daily activities. Moreover, in case of exacerbations, it could affect the lifestyle and well-being of the individual. Behavioral changes made in this period have a noteworthy effect on the performance of families. These effects might lead to child abuse, criminal behavior as well as incompatibility with the spouse and a decrease in the quality of marital relationships $(6,7)$.

While men do not experience the effects of premenstrual physical and emotional changes directly, premenstrual changes might affect men by changing the dynamics of relationships (6) which could result in frustration, confusion, and helplessness (8-10). Although the PMS is a serious condition, it has received scant attention so far. Due to the absence of research on the subject and considering the high prevalence of PMS among married women of reproductive age and men's insufficient awareness of the subject along with the impact of this disorder on their lives and marital satisfaction, the need for the present investigation seems evident. The purpose of this study was to determine awareness, attitude, and performance of men regarding PMS among the patients who referred to the selected health centers of Urmia in 2016.

Received 3 December 2017, Accepted 21 April 2018, Available online 12 May 2018

${ }^{1}$ Reproductive Health Research Center, Midwifery Department, Urmia University of Medical Sciences, Urmia, Iran. ${ }^{2}$ Faculty of Nursing and Midwifery, Urmia University of Medical Sciences. Student Research Committee of Urmia University of Medical Sciences, Urmia, Iran. *Corresponding Author: Atefeh Yas, Tel: xxx, Fax: +984432754921. Email: Atefehyas@yahoo.com 


\section{Materials and Methods}

This is a cross-sectional study that was conducted among the husbands of the women who kept referring to some of the health centers of Urmia in 2016.

\section{Sampling}

The study population was the husbands of the women who referred to health centers of Urmia in which the sample size of the study was considered to be 150 based on the study conducted by Morowati Sharifabad et al (11). After obtaining the necessary permits and authorization from 4 different regions of Urmia, 4 health centers were randomly selected based on economic and social perspectives. Then, the available husbands of the women referring to those health centers were contacted. The inclusion criteria for the study consisted of literacy, at least 6 months of marriage, and not being pregnant.

\section{Tools}

The present study used awareness and performance questionnaire (11) designed to estimate the awareness and performance of men regarding PMS. This questionnaire consisted of 3 parts. The first part targeted demographic information, the second part focused on PMS awareness (including 18 items concerning the mental indications of PMS, 18 questions regarding physical symptoms of PMS, and 15 items on preventing or reducing PMS symptoms ranging from zero score to 51 based on the answers), and the third part included 8 questions about men's performance regarding PMS (options comprised never, rarely, sometimes, or always ranging from 8 to 32 score based on the answers). The attitude questionnaire contained 12 questions based on the options of strongly disagree, disagree, unsure, agree and strongly agree (ranging from 1 to 5), and the minimum to maximum scores were set 12 to 60 , respectively. The validity and reliability of the awareness and performance questionnaires in the present study were verified by Morowati Sharifabad et al and Cronbach $\alpha$ for the awareness and performance was found to be 0.83 and 0.78 , respectively (11). The content validity of the attitude questionnaire was assessed by 5 members of the Faculty of the Department of Obstetrics and Gynecology, Urmia University of Medical Sciences, Urmia, Iran. Based on their comments, the necessary adjustments were made to the questionnaire. In addition, its reliability was estimated using the test-retest method and the Cronbach a was 0.72 .

Data Analysis

The collected data were analyzed using SPSS version 19.0. Pearson correlation coefficient and $t$ test were utilized to determine the relationship between factors.

\section{Results}

Data analysis showed that the mean age of the studied subjects was $33.82 \pm 7.41$ while their wives' age was
$29 \pm 7.71$ and the mean length of marriage was $7.42 \pm 2.24$ (Table 1).

In this study, $22 \%$ of the women have had at least one mood or physical symptoms of PMS in 3 of their previous menstrual cycles.

In response to questions regarding awareness of psychological symptoms, most of the correct answers belonged to fatigue while the least correct answers were about overeating and food cravings. Regarding awareness of the physical symptoms, most of the correct answers belonged to breast pain and tenderness, whereas the least correct answers were about backache. In response to questions regarding strategies for prevention of PMS, most of the correct answers comprised affection towards the husband whereas the least correct answers were about weight loss. The frequency and percentage of correct and wrong answers concerning awareness of psychological and physical symptoms as well as prevention strategies for PMS are presented in Table 2.

The overall mean score of men for prevention strategies, psychological, and physical symptoms of PMS was found to be $25.2 \pm 4.45$. This mean score was reported to be $25.36 \pm 5.36$ in men whose wives had PMS while it was

Table 1. Demographic Characteristics of Men Participated in the Study

\begin{tabular}{|c|c|c|}
\hline Variable & Category & No. (\%) \\
\hline \multirow{5}{*}{ Education of Man } & Cycle & $19(12.7)$ \\
\hline & High school & $13(8.7)$ \\
\hline & Diploma & $35(23.3)$ \\
\hline & Associate degree & $7(4.7)$ \\
\hline & Bachelor's degree or higher & $76(50.7)$ \\
\hline \multirow{6}{*}{$\begin{array}{l}\text { Education of } \\
\text { women }\end{array}$} & Unlettered & $3(2)$ \\
\hline & Cycle & $27(18.8)$ \\
\hline & High school & $15(10)$ \\
\hline & Diploma & $35(23.3)$ \\
\hline & Associate degree & $10(6.7)$ \\
\hline & Bachelor's degree or higher & $53(39.3)$ \\
\hline \multirow{4}{*}{$\begin{array}{l}\text { Employment status } \\
\text { of men }\end{array}$} & Employee & $68(45.3)$ \\
\hline & Self-employed & $72(48)$ \\
\hline & Working & $9(6)$ \\
\hline & Unemployed & $1(0.7)$ \\
\hline \multirow{2}{*}{$\begin{array}{l}\text { Employment status } \\
\text { of women }\end{array}$} & Practitioner & $52(34.7)$ \\
\hline & Housewife & $98(65.3)$ \\
\hline \multirow{3}{*}{$\begin{array}{l}\text { The economic } \\
\text { situation }\end{array}$} & Income more than spending & $5(3.3)$ \\
\hline & Income to spend & $108(72)$ \\
\hline & Less income to spend & $37(24.7)$ \\
\hline \multirow{5}{*}{ Number of children } & No & $60(40)$ \\
\hline & 1 & $37(24.7)$ \\
\hline & 2 & $27(19.3)$ \\
\hline & 3 & $16(10.7)$ \\
\hline & 4 & $8(5.3)$ \\
\hline
\end{tabular}


Table 2. Frequency of Awareness of Men Regarding Psychological and Physical Symptoms as well as Prevention Strategies of PMS

\begin{tabular}{|c|c|c|}
\hline & $\begin{array}{l}\text { False } \\
\text { No. (\%) }\end{array}$ & $\begin{array}{l}\text { Correct } \\
\text { No. (\%) }\end{array}$ \\
\hline \multicolumn{3}{|c|}{ Psychological Symptoms } \\
\hline 1. Fatigue & 23(15.3) & $127(84.7)$ \\
\hline 2. Irritability & $53(38.7)$ & $92(62.3)$ \\
\hline 3. Hope for the future & $(39.3) 59$ & $91(60.7)$ \\
\hline 4. Cried attacks & $50(33.3)$ & $100(66.7)$ \\
\hline 5. Increased libido & $73(48.7)$ & $77(51.3)$ \\
\hline 6. Socialize & $71(47.3)$ & 79(52.7) \\
\hline 7. Forgetfulness and loss of concentration & $88(58.7)$ & $62(41.3)$ \\
\hline 8. Sleep disorder & $90(60)$ & $60(40)$ \\
\hline 9. Oversleeping & $57(38)$ & $93(62)$ \\
\hline 10. Social isolation & $42(28)$ & $108(72)$ \\
\hline 11. Decreased libido & $138(92)$ & $12(8)$ \\
\hline 12. Increased power & $31(20.7)$ & 119(79.3) \\
\hline 13.Suicidal thoughts & $86(57.3)$ & $64(42.7)$ \\
\hline 14. Depression & $53(35.3)$ & $97(64.7)$ \\
\hline 15. Masochism & $80(53.3)$ & $70(46.7)$ \\
\hline 16. Overeating/food cravings & $141(94)$ & $9(6)$ \\
\hline 17. Happiness & $32(21.3)$ & $118(78.7)$ \\
\hline 18. Feel upset & $103(68.7)$ & $47(31.3)$ \\
\hline \multicolumn{3}{|l|}{ Physical Symptoms } \\
\hline 1. Headache & $72(48)$ & $78(52)$ \\
\hline 2. Hair loss & $83(55.3)$ & $67(44.7)$ \\
\hline 3. Bruises nails & $78(52)$ & $72(48)$ \\
\hline 4. Acne & $86(57.3)$ & $64(42.7)$ \\
\hline 5. Mastalgia & $34(22.7)$ & $116(77.3)$ \\
\hline 6. Loss of appetite & $124(82.7)$ & $26(17.3)$ \\
\hline 7. Back ache & $140(93.3)$ & $10(6.7)$ \\
\hline 8. Increased appetite & 136(90.7) & $14(9.3)$ \\
\hline 9. Flatulence & $89(59.3)$ & $61(40.7)$ \\
\hline 10. Blurred vision & $81(54)$ & $69(46)$ \\
\hline 11. Joint and muscle pain & $67(44.7)$ & $83(55.3)$ \\
\hline 12. Weight Gain & $125(83.3)$ & $25(16.7)$ \\
\hline $\begin{array}{l}\text { 13. Gastrointestinal disorder, constipation } \\
\text { / diarrhea }\end{array}$ & $73(48.7)$ & $77(51.3)$ \\
\hline 14. Feeling cold & $122(81.3)$ & $28(18.7)$ \\
\hline 15. Dizziness & $120(80)$ & $30(20)$ \\
\hline 16. Hot flashes/sweats & $72(48)$ & $78(52)$ \\
\hline 17. Heart beat & $68(45.3)$ & $82(54.7)$ \\
\hline 18. Eye irritation & $51(34)$ & $99(66)$ \\
\hline \multicolumn{3}{|c|}{ Prevention Methods From PMS } \\
\hline 1. Walking or aerobic exercise & $87(52)$ & $72(48)$ \\
\hline 2. Hot drinks and herbal & $22(14.7)$ & $128(85.3)$ \\
\hline
\end{tabular}

Table 2. Continued

\begin{tabular}{|c|c|c|}
\hline & $\begin{array}{l}\text { False } \\
\text { No. (\%) }\end{array}$ & $\begin{array}{l}\text { Correct } \\
\text { No. (\%) }\end{array}$ \\
\hline 3. Red meat & $140(93.3)$ & $10(6.7)$ \\
\hline 4. Eating fresh vegetables and fruits & $57(38)$ & $93(62)$ \\
\hline 5. Lack of mobility and exercise & $90(60)$ & $60(40)$ \\
\hline 6. Seafood consumption & $125(85.3)$ & $22(14.7)$ \\
\hline 7. Weight Loss & $132(88)$ & $18(12)$ \\
\hline 8. Attention and support from wife & $11(7.3)$ & 139(92.7) \\
\hline 9. Prevention of discussions and fights & $24(16)$ & $126(84)$ \\
\hline 10. Ignoring symptoms & $71(47.3)$ & $79(52.7)$ \\
\hline 11. Enough rest & $28(18.7)$ & $122(81.3)$ \\
\hline $\begin{array}{l}\text { 12. The woman left alone to improve } \\
\text { symptoms }\end{array}$ & $85(56.7)$ & $65(43.3)$ \\
\hline 13. Eat snacks between main meals & $78(52)$ & $72(48)$ \\
\hline $\begin{array}{l}\text { 14. Female companionship in leisure and } \\
\text { work that helps improving }\end{array}$ & 23(15.3) & $127(84.7)$ \\
\hline 15. See a doctor and treat symptoms & $34(22.7)$ & $116(77.3)$ \\
\hline
\end{tabular}

$24.92 \pm 4.18$ in men whose wives did not suffer from PMS. This difference was not statistically significant (Table 3; $P=0.61$ ).

The frequencies of responses regarding questions about the performance and attitude of PMS are presented in Tables 4 and 5 , respectively.

The mean score of performance in men with wives suffering from PMS was higher compared to the other men, but this was not statistically significant $(P=0.52)$. The mean scores of attitude in men with wives suffering from PMS and other men were found to be $41.34 \pm 6.10$ and $43.59 \pm 4.88$, respectively. This difference was statistically significant $(P=0.04)$ (Table 6).

Pearson correlation coefficient revealed a significant relationship among awareness, attitude, and performance of men regarding PMS (Table 7).

\section{Discussion}

In the present study, $22 \%$ of the surveyed women suffered from PMS. In the study conducted by Bokaie et al, the frequency of PMS was estimated to be $91.3 \%$ (12). Abbasi et al found that $86 \%$ of teenage girls showed the symptoms (13). Cheng et al revealed that 39\% of the university students were diagnosed with PMS (14). The statistical differences observed in these studies are probably due to the age groups of the studied subjects in this investigation compared to the above-cited ones.

Most of the symptoms observed in the wives of the men who participated in the study were emotional symptoms of PMS. In the study of Acikgoz et al, there was a significant relationship between PMS and risk of depression. Students with PMS showed symptoms of depression (15). Yamazaki also showed that at the end of the Luteal cycle, women's 
Table 3. The Mean Scores of Prevention Strategies, Psychological, and Physical Symptoms of PMS in Men Whose Wives Had PMS Compared to Men Whose Wives Did not Suffer From PMS

\begin{tabular}{lll}
\hline Awareness & PMS $-(\mathbf{n = 1 1 7}, \mathbf{7 8 \%})$ & PMS + (n=33, 22\%) \\
\hline Psychological & $9.47 \pm 2.56$ & $9.57 \pm 2.62$ \\
Physical & $7.16 \pm 2.08$ & $7.30 \pm 2.41$ \\
Prevention of PMS & $8.28 \pm 2.05$ & $8.48 \pm 2.16$ \\
Total & $24.92 \pm 4.18$ & $25.36 \pm 5.36$ \\
\hline
\end{tabular}

Note: $P$ value $=0.61, t$ test.

emotions are more affected and they had longer reaction times to all emotional stimuli and a significantly reduced response to happy faces (16). Bokaie et al (12) conducted an investigation on the frequency of the symptoms of PMS in which the most common symptoms reported by women were physical symptoms. This finding was also verified by Kiani et al (17).

In the present study, most of the correct answers regarding awareness were recorded about depression, social isolation, fatigue, and bouts of crying. The finding of a study by Morowati Sharifabad et al (11) was in line with the results of the present study revealing that the most correct answers dealt with fatigue, lethargy, and irritability. Makuch et al also found that 55\% of men showed a good percentage of awareness regarding psychological symptoms of PMS (18). Fifty to $60 \%$ of men in an investigation conducted by Christensen and Oei believed that PMS appears with negative emotional symptoms in women such as instability, anger, anxiety, and fatigue (19). Furthermore, Brooks-Gunn and Ruble revealed that most of the men think women tend to get irritated in the pre-menstrual period (20). The results of the mentioned studies are all in line with the present investigation.

The current study found that the highest awareness of men regarding physical PMS symptoms was about breast pain and tenderness. Moreover, $60.7 \%$ of the wives of these men complained about fluid retention including weight gain, swelling of extremities, breast tenderness,

Table 4. Frequency of Men's Responses to Performance Questions

\begin{tabular}{|c|c|c|c|c|}
\hline Items & $\begin{array}{l}\text { Always } \\
\text { No. (\%) }\end{array}$ & $\begin{array}{c}\text { Sometimes } \\
\text { No. (\%) }\end{array}$ & $\begin{array}{l}\text { Rarely } \\
\text { No. (\%) }\end{array}$ & $\begin{array}{l}\text { Never } \\
\text { No. (\%) }\end{array}$ \\
\hline 1. I pay more attention to my wife when symptoms of premenstrual are observed & $66(44)$ & 64(42.7) & $17(11.3)$ & $3(2)$ \\
\hline 2. I prefer not to argue with my wife during the premenstrual period & $58(38.7)$ & $65(43.3)$ & $24(16)$ & $3(2)$ \\
\hline 3. I control myself and try not to get angry when symptoms of premenstrual are observed. & $52(34.7)$ & $69(46)$ & $25(16.7)$ & $3(2)$ \\
\hline $\begin{array}{l}\text { 4. I attend to my wife the most, express my love, and reassure her during her premenstrual } \\
\text { period }\end{array}$ & $46(30.7)$ & $71(47.3)$ & 28(18.7) & $4(2.7)$ \\
\hline $\begin{array}{l}\text { 5. I call my wife from the work every few hours and remind her to eat something during } \\
\text { her premenstrual period }\end{array}$ & 24(16) & $63(42)$ & $49(32.7)$ & $14(9.3)$ \\
\hline $\begin{array}{l}\text { 6. At the end of this period, I talk about these issues with my wife and assure her that I am } \\
\text { on her side }\end{array}$ & $24(16)$ & $65(43.3)$ & $52(34.7)$ & $8(5.3)$ \\
\hline $\begin{array}{l}\text { 7. I keep the house warm and intimate so as she remain calm during her premenstrual } \\
\text { period }\end{array}$ & $41(27.3)$ & $69(46)$ & $37(24.7)$ & $3(2)$ \\
\hline 8. I go along with my wife's exercise and diet schedule in this period & $37(24.7)$ & $63(42)$ & $41(27.3)$ & $9(6)$ \\
\hline
\end{tabular}

Table 5. Frequency of Men's Responses to Attitude Questions

\begin{tabular}{|c|c|c|c|c|c|}
\hline The Attitude Towards PMS & $\begin{array}{l}\text { I strongly } \\
\text { Disagree }\end{array}$ & $\begin{array}{l}\text { I oppose } \\
\text { this idea }\end{array}$ & $\begin{array}{l}\text { I don't } \\
\text { know }\end{array}$ & I agree & $\begin{array}{l}\text { I unequivocally } \\
\text { concur }\end{array}$ \\
\hline 1. Premenstrual symptoms are a natural phenomenon for women. & $3(2)$ & 14(9.3) & 25(16.7) & $85(56.7)$ & 22(14.7) \\
\hline 2. Women with premenstrual mental symptoms stay at home. & $22(14.7)$ & $81(54)$ & $18(12)$ & 24(16) & $1(0.7)$ \\
\hline 3. Symptoms are related to menstrual fiction. & 16(10.7) & $84(56)$ & $37(24.7)$ & $11(7.3)$ & $1(0.7)$ \\
\hline 4. Compatibility with my wife's PMS is easy. & $0(0)$ & $24(16)$ & $17(11.3)$ & $88(58.7)$ & 21(14) \\
\hline 5. Training is essential in controlling premenstrual symptoms. & $2(1.3)$ & $8(5.3)$ & 20(13.3) & $90(60)$ & $30(20)$ \\
\hline 6. Any activity can control premenstrual symptoms. & $11(7.3)$ & $76(50.6)$ & $43(28.7)$ & $15(10)$ & $3(2)$ \\
\hline 7. The women are just making excuses when claim to have PMS. & 20(13.3) & $89(59.3)$ & $34(22.7)$ & $5(3.3)$ & $1(0.7)$ \\
\hline $\begin{array}{l}\text { 8. Women worry should if they get emotional symptoms a few days } \\
\text { before menstruation. }\end{array}$ & $14(9.3)$ & $96(64)$ & 26(17.3) & $12(8)$ & $1(0.7)$ \\
\hline 9. PMS could be cured only with drugs. & $9(6)$ & $67(44.7)$ & 29(19.3) & $37(24.7)$ & $3(2)$ \\
\hline 10. The only thing women can do enduring PMS? & $5(3.3)$ & $86(57.3)$ & $33(22)$ & $24(16)$ & $1(0.7)$ \\
\hline 11 Only a doctor can treat premenstrual symptoms. & $8(5.3)$ & $48(32)$ & $43(28.7)$ & $47(31.3)$ & $3(2)$ \\
\hline $\begin{array}{l}\text { 12. Women have to inform their relatives of the occurrence of } \\
\text { premenstrual symptoms. }\end{array}$ & $3(2)$ & $33(22)$ & $14(9.3)$ & $79(52.7)$ & 21(14) \\
\hline
\end{tabular}


Table 6. Comparison of the Attitude and Performance of 2 Groups of Men Regarding Women's PMS ${ }^{a}$

\begin{tabular}{lcccc}
\hline & $\begin{array}{c}\text { PMS + } \\
\text { (n= 33, 22\%) }\end{array}$ & $\begin{array}{c}\text { PMS - } \\
\text { (n= 117, 78\%) }\end{array}$ & Total & P Value $^{\mathrm{b}}$ \\
\hline Attitude & $41.34 \pm 6.10$ & $43.59 \pm 4.88$ & $43.10 \pm 5.23$ & 0.04 \\
Performance & $24.48 \pm 5.09$ & $23.79 \pm 5.43$ & $23.93 \pm 5.35$ & 0.52 \\
\hline
\end{tabular}

a Men's score with wives suffering from PMS was higher from the others. ${ }^{\mathrm{b}} t$ test.

Table 7. Relationship Among Awareness, Attitude, and Performance of Men Regarding PMS

\begin{tabular}{llll}
\hline & Awareness & Attitude & Performance \\
\hline Awareness & & $P=0.000^{*}$ & $P=0.000^{*}$ \\
Attitude & & & $P=0.000^{*}$ \\
Performance & $P=0.000^{*}$ & & \\
\hline
\end{tabular}

*Pearson Test.

and bloating. It could be deduced that the most correct answers of men in the present study were the most frequent physical symptoms of PMS in women.

The most correct answers concerning prevention of PMS belonged to hot drinks and herbal, expression of affection to one's wife, argument and fight avoidance, and taking care of women in these situations. Likewise, in the study done by Morowati Sharifabad et al (11), the most correct answers regarding prevention of PMS were categorized as spousal support, attention to her, and not leaving her alone which are in accordance with the finding of the present research. As most of the PMS symptoms reported by men's wife participating in this study were emotional and fluid retention, it seems that this high level of awareness has given good strategies to men for keeping their wives under control. In addition, as the results indicate, the husbands of the women with PMS got a better score in comparison to others.

Men whose wives had PMS recorded a better awareness score compared to those whose wives did not suffer from PMS, but this difference was not statistically significant. It could be concluded that PMS symptoms in women were the reason for the increase in men's awareness of the matter.

In the present research, $71 \%$ of the surveyed men believed that PMS is a natural phenomenon for women while Makuch et al found that only $34 \%$ of men had such a conviction (18). Brooks-Gunn and Ruble found that most of the men think PMS has debilitating effect on women's life and affects it negatively (20). The difference in the results might have occurred due to the fact that, in the reported studies, all the wives of participating men had PMS, while in the present study this number was only $22 \%$. As the comparison of the attitudes in the 2 groups demonstrated, men whose wives suffer from PMS got a lower attitude score than the others. This difference was statistically significant. It could be concluded that symptoms cause problems in the marital relationship, undermine the quality of life, and change the attitude of people toward the problem.

There was a significant correlation among awareness, attitude and performance of men meaning that the increase of awareness results in a more positive attitude and a better attitude leads to better performance regarding their wives PMS which is theoretically rational.

\section{Conclusions}

In the present study, men whose wives had PMS got a better awareness and performance score but a lower attitude score once compared to other men. Equally, there was a critical connection between and among awareness, attitude, and performance of men regarding their wives' PMS. Besides, men reported emotional symptoms in their wives more frequently and showed a higher level of awareness in this area than they did for physical symptoms. This proves that emotional symptoms affect men more in the premenstrual period.

\section{Limitations}

The main limitation in the present study was lack of similar research studies regarding awareness, attitude, and performance of men regarding their wives' PMS to get a better perspective in discussion and conclusion of this article. In this investigation, not all of the wives of the participating men suffered from PMS, and this might affect the awareness, attitude, and performance of men regarding PMS. Thus, it is suggested that another study be conducted with men whose spouses suffer from PMS.

\section{Conflict of Interests}

Authors declare that they have no conflict of interests.

\section{Ethical Issues}

The present study was approved by the Research Ethics Committee of the Urmia University of Medical Sciences (IR.UMSU.REC.1393.36). All information about individuals was kept completely confidential and the research units were assured that the results are to be reported collectively.

\section{Financial Support}

Urmia University of Medical Sciences, Urmia, Iran.

\section{Acknowledgments}

We appreciate the Student Research Committee of Urmia University of Medical Sciences for providing financial support. We also thank the staff of health centers and the men who participated in this study.

\section{References}

1. Abdollahi Fard S, Dolatian M, Heshmat R, Alavi Majd H. Effect of foot reflexology on physical and psychological symptoms of premenstrual syndrome. Pejouhandeh. 
2013;18(1):8-15.

2. Sadock BJ, Sadock VA. Kaplan and Sadock's Synopsis of Psychiatry: Behavioral Sciences/Clinical Psychiatry. Lippincott Williams \& Wilkins; 2011.

3. Berek JS, Novak E. Berek \& Novak’s Gynecology. Lippincott Williams \& Wilkins; 2012.

4. Lee JC, Yu BK, Byeon JH, Lee KH, Min JH, Park SH. A study on the menstruation of Korean adolescent girls in Seoul. Korean J Pediatr. 2011;54(5):201-206. doi:10.3345/ kjp.2011.54.5.201

5. Fernandez I, Reid C, Dziurawiec S. Living with endometriosis: the perspective of male partners. J Psychosom Res. 2006;61(4):433-438. doi:10.1016/j. jpsychores.2006.06.003

6. Ryser R, Feinauer LL. Premenstrual syndrome and the marital relationship. Am J Fam Ther. 1992;20(2):179-190. doi:10.1080/01926189208250887

7. Morowati Sharifabad MA, Karimian Kakolaki Z, Bokaie M, Fallahzadeh H, Mirrezaii S. Frequency of Marital Dissatisfaction in Couples With Wives Who Suffer From Premenstrual Syndrome in The City of Yazd. Health System Reserch. 2014;10(2):315-325.

8. Cortese J, Brown MA. Coping responses of men whose partners experience premenstrual symptomatology. J Obstet Gynecol Neonatal Nurs. 1989;18(5):405-412. doi:10.1111/j.1552-6909.1989.tb00494.x

9. Davey SJ, Dziurawiec S, O’Brien-Malone A. Men's voices: postnatal depression from the perspective of male partners. Qual Health Res. 2006;16(2):206-220. doi:10.1177/1049732305281950

10. Rundle R. A Qualitative Exploration of Couples' Relational Experiences when One Partner Suffers from Symptoms of PMS: A Systems Approach. ProQuest Information and Learning Company's UMI Dissertation Services; 2005.

11. Morowati Sharifabad MA, Karimian Kakolaki Z, Bokaie M, Fallahzadeh H, Gerayllo S, Farhmand AM. Study of knowledge and practice of men with wives who suffer from premenstrual syndrome about the syndrome in yazd city school of public health,Yazd. Toloo-e-Behdasht. 2013;14(3):95-110. [Persian].

12. Morowati Sharifabad MA, Karimian Kakolaki Z, Bokaie M, Enjezab B, Gerayllo S, Motaghi B. Evaluation of the frequency of clinical manifestations of premenstrual syndrome in young married women in Yazd. Community Health Journal. 2014;8(3):45-53.

13. Abbasi S, Tufail A, Kalyar J, Ahsan NA. Pre menstrual syndrome in undergraduate medical students: Hostellers versus day-scholars. J Surg Pak Int. 2015;20:3.

14. Cheng SH, Shih CC, Yang YK, Chen KT, Chang YH, Yang YC. Factors associated with premenstrual syndrome - a survey of new female university students. Kaohsiung J Med Sci. 2013;29(2):100-105. doi:10.1016/j.kjms.2012.08.017

15. Acikgoz A, Dayi A, Binbay T. Prevalence of premenstrual syndrome and its relationship to depressive symptoms in first-year university students. Saudi Med J. 2017;38(11):1125-1131. doi:10.15537/smj.2017.11.20526

16. Yamazaki M, Tamura K. The menstrual cycle affects recognition of emotional expressions: an event-related potential study. F1000Res. 2017;6:853. doi:10.12688/ f1000research.11563.1

17. Kiani AA, Heydari M, Mohammadi TS, Faghihzadeh S. Prevalence, signs, symptoms and predisposing factors of premenstrual syndromes in employed women. Daneshvar Medicine 2009;16(81):45-54. [Persian].

18. Makuch MY, Osis MJ, de Padua KS, Bahamondes L. Understanding and attitudes of Brazilian men with regard to premenstrual syndrome. Int J Gynaecol Obstet. 2013;121(1):31-34. doi:10.1016/j.ijgo.2012.10.020

19. Christensen AP, Oei TP. Men's perception of premenstrual changes on the premenstrual assessment form. Psychol Rep. 1990;66(2):615-619. doi:10.2466/pr0.1990.66.2.615

20. Brooks-Gunn J, Ruble DN. Men's and women's attitudes and beliefs about the menstrual cycle. Sex Roles. 1986;14(5):287299. doi: $10.1007 / \mathrm{bf} 00287580$

(c) 2018 The Author (s); This is an open-access article distributed under the terms of the Creative Commons Attribution License (http://creativecommons.org/licenses/by/4.0), which permits unrestricted use, distribution, and reproduction in any medium, provided the original work is properly cited. 